\title{
Erratum to: Personality traits are consistent when measured in the field and in the laboratory in African striped mice (Rhabdomys pumilio)
}

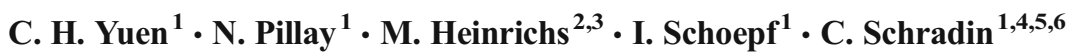

Published online: 21 September 2016

(C) Springer-Verlag Berlin Heidelberg 2016

Erratum to: Behavioral Ecology and Sociobiology 70(8):

1235-1246

DOI: 10.1007/s00265-016-2131-1

The original version of this article contained a mistake in

Tables 2 and 3. Correct tables are presented here.

The online version of the original article can be found at http://dx.doi. org/10.1007/s00265-016-2131-1.

C. H. Yuen

bt8205@yahoo.co.uk

1 School of Animal, Plant and Environmental Sciences, University of the Witwatersrand, Johannesburg, South Africa

2 Department of Psychology, Laboratory for Biological and Personality Psychology, University of Freiburg,

D-79104 Freiburg, Germany

3 Freiburg Brain Imaging Center, University Medical Center, University of Freiburg, D-79106 Freiburg, Germany

4 Department of Animal Behaviour, Institute of Evolutionary Biology and Environmental Studies, University of Zurich, Zurich, Switzerland

5 IPHC-DEPE, Université de Strasbourg, 23 rue Becquerel, 67087 Strasbourg, France

6 CNRS, UMR7178, 67087 Strasbourg, France 
Table 2

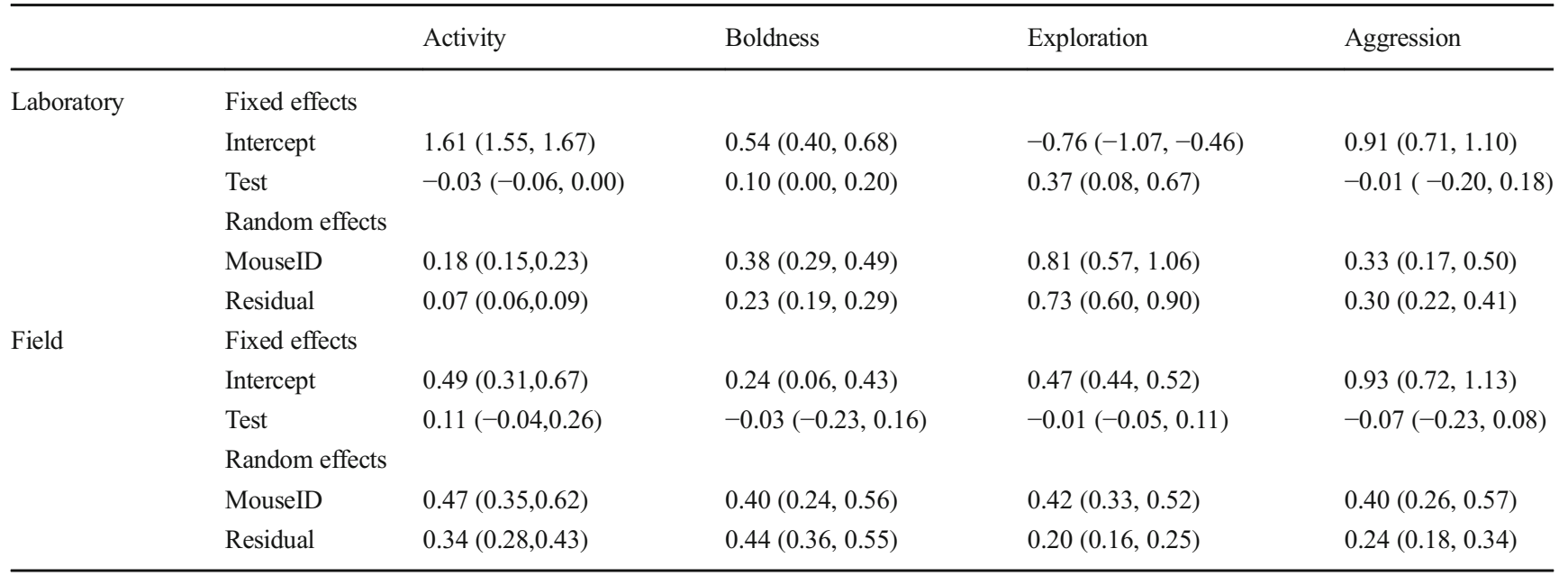

Table 3

\begin{tabular}{lllll}
\hline & Activity & Boldness & Exploration & Aggression \\
\hline Fixed effects & & & & \\
$\quad$ Intercept & $2.34(1.18,3.53)$ & $0.03(-0.21,0.27)$ & $0.69(0.57,0.81)$ & $1.10(0.97,1.24)$ \\
$\quad$ Test & $0.08(-0.07,0.22)$ & $-0.07(-0.27,0.12)$ & $-0.03(-0.11,0.04)$ & $-0.09(-0.27,0.08)$ \\
$\quad$ Laboratory score & $-1.15(-1.88,-0.44)$ & $0.40(0.09,0.70)$ & $0.17(0.10,0.23)$ & $0.36(0.29,0.49)$ \\
Random effects & & & & $0.05(0.00,0.24)$ \\
$\quad$ MouseID & $0.45(0.33,0.59)$ & $0.36(0.17,0.50)$ & $0.35(0.27,0.44)$ & $0.28(0.20,0.35)$ \\
$\quad$ Residual & $0.32(0.26,0.40)$ & $0.44(0.36,0.55)$ & $0.18(0.15,0.22)$ & \\
\hline
\end{tabular}

